03

\title{
Детонация горючей газовой смеси при взаимодействии ударной волны с эллиптической областью тяжелого инертного газа
}

\author{
(С) П.Ю. Георгиевский, В.А. Левин, О.Г. Сутырин ฯ \\ Научно-исследовательский институт механики Московского государственного университета им. М.В. Ломоносова, \\ Москва, Россия \\ ฯE-mail: sutyrin@imec.msu.ru
}

Поступило в Редакцию 9 декабря 2020 г.

В окончательной редакции 2 февраля 2021 г.

Принято к публикации 3 февраля 2021 г.

На основе уравнений Эйлера численно моделируется взаимодействие ударной волны в горючем газе с эллиптическим пузырем инертного газа повышенной плотности в плоской двумерной постановке. Применяется метод конечных объемов годуновского типа второго порядка аппроксимации. Горение газа моделируется с помощью двухстадийной кинетики Коробейникова-Левина. Рассмотрены различные значения числа Маха падающей волны и степени удлинения инертного пузыря, описаны преломление и фокусировка падающей волны. Обнаружены качественно различные режимы инициирования детонации газа, включая прямое инициирование сильной волной, воспламенение при отражении волны средней интенсивности от границы газов и при фокусировке вторичных скачков уплотнения при меньших числах Маха волны. Определена зависимость режима воспламенения от интенсивности волны и формы пузыря.

Ключевые слова: ударная волна, газовый пузырь, фокусировка, кумуляция, газовая детонация, воспламенение.

DOI: 10.21883/PJTF.2021.09.50902.18651

Взаимодействие ударных волн с локальными неоднородностями имеет место в широком круге течений: от космических процессов со сверхновыми звездами до систем высокоскоростного сгорания и инерционного термоядерного синтеза. Такие течения часто исследуются на основе задачи о взаимодействии ударной волны с газовым пузырем (shock-bubble interaction, SBI), в том числе химически реагирующим (RSBI), включающей широкий спектр ударно-волновых эффектов, типов неустойчивостей и видов волн реакции. После проведения первых экспериментов [1] в последние годы эта задача активно исследуется. В недавнем цикле численных исследований [2-4] было обнаружено существенное влияние начального давления смеси и интенсивности падающей волны на тип воспламенения пузыря (дефлаграцию или детонацию), а также значительное уменьшение интенсивности перемешивания газов в результате воздействия волны реакции.

Известно несколько ключевых явлений, сопутствующих взаимодействию ударной волны с газовым пузырем: неоднородное ускорение и деформация пузыря, генерация крупно- и мелкомасштабной завихренности, турбулентное перемешивание газов и фокусировка поперечных скачков уплотнения. Последний эффект представляет особый интерес как новый метод инициирования горения газовых смесей и поэтому также активно исследуется в настоящее время. Известно, что все основные параметры задачи - интенсивность падающей волны, плотность газа в пузыре и его форма - играют важную роль при определении режима преломления волны и интенсивности фокусировки [5]. В недавней работе [6] было обнаружено существенное влияние формы реагирующего газового пузыря, находящегося в инертном газе, на режим воспламенения и критическое число Маха падающей волны.

Явление фокусировки ударной волны не связано с реакционной способностью газа в пузыре, поэтому можно ожидать, что наличие такой „газодинамической линзы“ окажется важным при воспламенении горючих смесей и в более широком классе течений. В настоящей работе численно исследуется „инвертированная“ по отношению к рассмотренной в работе [6] задача, а именно взаимодействие ударной волны, распространяющейся в горючей газовой смеси, с цилиндром тяжелого инертного газа эллиптического сечения.

Двумерные плоские течения газовой смеси моделируются с помощью уравнений Эйлера для совершенного газа с неоднородным распределением молярной массы:

$$
\frac{\partial}{\partial t}\left(\begin{array}{c}
\rho \\
\rho u \\
\rho v \\
\rho \alpha \\
\rho \beta \\
\rho \mu
\end{array}\right)+\frac{\partial}{\partial x}\left(\begin{array}{c}
\rho u \\
p+\rho u^{2} \\
\rho u v \\
(\rho e+p) u \\
\rho u \alpha \\
\rho u \beta \\
\rho u \mu
\end{array}\right)+\frac{\partial}{\partial y}\left(\begin{array}{c}
\rho v \\
\rho u v \\
p+\rho v^{2} \\
(\rho e+p) v \\
\rho v \alpha \\
\rho v \beta \\
\rho v \mu
\end{array}\right)=\left(\begin{array}{c}
0 \\
0 \\
0 \\
0 \\
\omega_{\alpha} \\
\omega_{\beta} \\
0
\end{array}\right),
$$

где $\rho, p, u, v$ - плотность, давление и компоненты скорости газа вдоль декартовых осей $x, y ; \mu$ - локальная молярная масса; $\alpha, \beta$ - параметры полноты протекания 


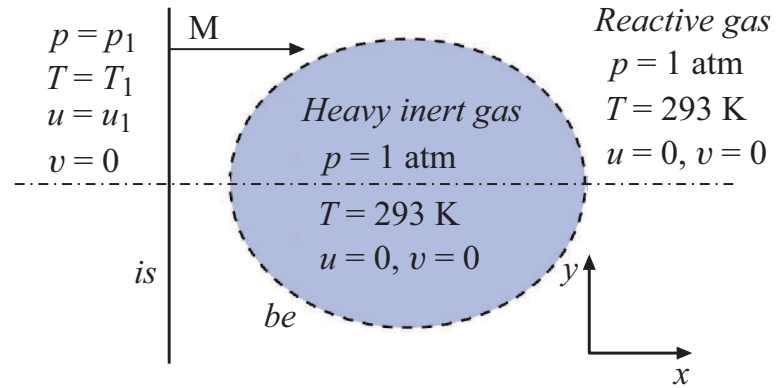

Рис. 1. Схема начальных условий: $i s-$ исходная ударная волна, be - граница инертного пузыря (газового цилиндра). Штрихпунктирной линией отмечена плоскость симметрии задачи.

химической реакции. Полная энергия единицы объема газа равна $\rho e=p /(\gamma-1)+\rho\left(u^{2}+v^{2}\right) / 2+\rho \beta Q$, где $\gamma=1.4$ - показатель адиабаты газа, а $Q-$ удельное тепловыделение химической реакции.

Химическая реакция описывается двухстадийной кинетикой Коробейникова-Левина [7] с параметрами реакции, соответствующими стехиометрической водородкислородной смеси, разбавленной аргоном [8,9]. Для таких параметров детонационная волна Чепмена-Жуге при нормальных условиях имеет характерное число Маха $\mathrm{M}_{C J}=4.8$, а ширины зон индукции и реакции равны $l_{i}=0.56 \mathrm{~mm}$ и $l_{r} \approx 0.8 \mathrm{~mm}$ соответственно.

Для численного моделирования применяется обеспечивающий второй порядок точности метод „MUSCL“ годуновского типа с ограничителем вариации газодинамических величин ван Лира и HLLC-методом решения локальных задач о распаде разрыва. Расчеты проводились на однородной квадратной расчетной сетке с размером ячейки $20 \mu \mathrm{m}$ обеспечивающей 23 и 40 ячеек на зоны индукции и реакции соответственно.

На рис. 1 приведены начальные условия задачи. Падающая ударная волна is распространяется слева направо по покоящейся горючей газовой смеси, содержащей пузырь (цилиндр) - эллиптическую область $b e$, заполненную тяжелым инертным газом, при нормальных условиях $\left(p=10^{5} \mathrm{~Pa}, T=293 \mathrm{~K}\right)$. Молярная масса тяжелого газа равна $94.71 \mathrm{~g} / \mathrm{mol}$, что в 3 раза превышает молярную массу горючей смеси (результирующее число Атвуда задачи равно 0.5). Такое значение числа Атвуда обеспечивает достаточную интенсивность фокусировки вторичных скачков уплотнения и высокую чувствительность режима фокусировки к изменению формы пузыря [5]. Однородное состояние газа за волной is задается числом Маха М в диапазоне от 2.0 до 3.5 посредством соотношений Ранкина-Гюгонио. Геометрия пузыря задается отношением диаметров $\eta=d_{x} / d_{y}$. Рассмотрены три формы пузыря: круглый $(\eta=1.0)$, вытянутый $(\eta=1.44)$ и сплюснутый $(\eta=0.7)$. Площадь сечения пузыря одинакова и равна $12.6 \mathrm{~cm}^{2}$, что соответствует круглому пузырю $4 \mathrm{~cm}$ в диаметре, исследовавшемуся в экспериментальной [1] и численных [2-4] работах.
В силу симметрии задачи в большинстве случаев моделировалась только верхняя половина течения с условием симметрии на нижней границе расчетной области. На остальных границах, достаточно удаленных от зоны взаимодействия волны с пузырем, применялось условие $\partial / \partial n=0$.

На рис. 2, $a, b$ приведены ключевые этапы преломления ударной волны на примере круглого пузыря при $\mathrm{M}=2.7$. При прохождении ударной волны в пузырь формируется выпуклый отраженный скачок уплотнения rs. Тяжелый газ ускоряется и сжимается в прошедшем скачке $t s$, так что деформированный пузырь $s b$ уменьшается в объеме. За счет бароклинного эффекта на боковой границе пузыря формируется дорожка вихрей $p v$. Из-за меньшей, чем в случае исходной волны, скорости распространения скачка $t s$ формируются поперечные скачки $t$ ts и тройные точки, движущиеся по диагонали к плоскости симметрии. При выходе прошедшего скачка $t s$ наружу внутрь пузыря отражается волна разрежения rew. Вскоре после этого происходит фокусировка скачков: выпуклая часть bis падающей волны и поперечные скачки отражаются от плоскости симметрии. В зависимости от параметров задачи фокусировка скачков может происходить как снаружи, так и внутри пузыря [5], и при этом наблюдается резкое повышение давления и температуры газа в области фокусировки.

Опираясь на эти данные, можно предположить существование как минимум двух режимов инициирования детонации. Во-первых, так как температура за отраженной волной $r s$ выше, чем за падающей волной $i s$, воспламенение смеси может происходить при отражении волны достаточной интенсивности от границы пузыря. Во-вторых, детонация смеси может быть инициирована в области фокусировки скачков в горючей смеси вблизи правого полюса пузыря.

В проведенных расчетах наблюдались оба упомянутых выше режима. Инициирование детонации при отражении волны (рис. 2, $d$ ) происходит при достаточной интенсивности падающей волны независимо от формы пузыря. Детонационная волна $d w$ формируется вблизи левого полюса пузыря после некоторой задержки и затем свободно распространяется по горючей смеси, со временем обгоняя исходную ударную волну. При этом вызванный детонацией скачок уплотнения $d d s$ распространяется по пузырю, также обгоняя прошедшую волну $t s$. Преломление более слабых падающих волн приводит к детонации смеси при фокусировке поперечных скачков вблизи правого полюса пузыря (рис. 2,c). Как и в описанном выше случае, детонационная волна со временем обгоняет ударные волны, а также генерирует дополнительные скачки уплотнения в инертном газе. При распространении детонации на ее фронте формируется типичная ячеистая структура с шириной ячейки около $0.5 \mathrm{~mm}$.

На основе серии расчетов для $2.0 \leq \mathrm{M} \leq 3.5$ и $0.7 \leq \eta \leq 1.44$ была получена примерная карта режимов 
$a$
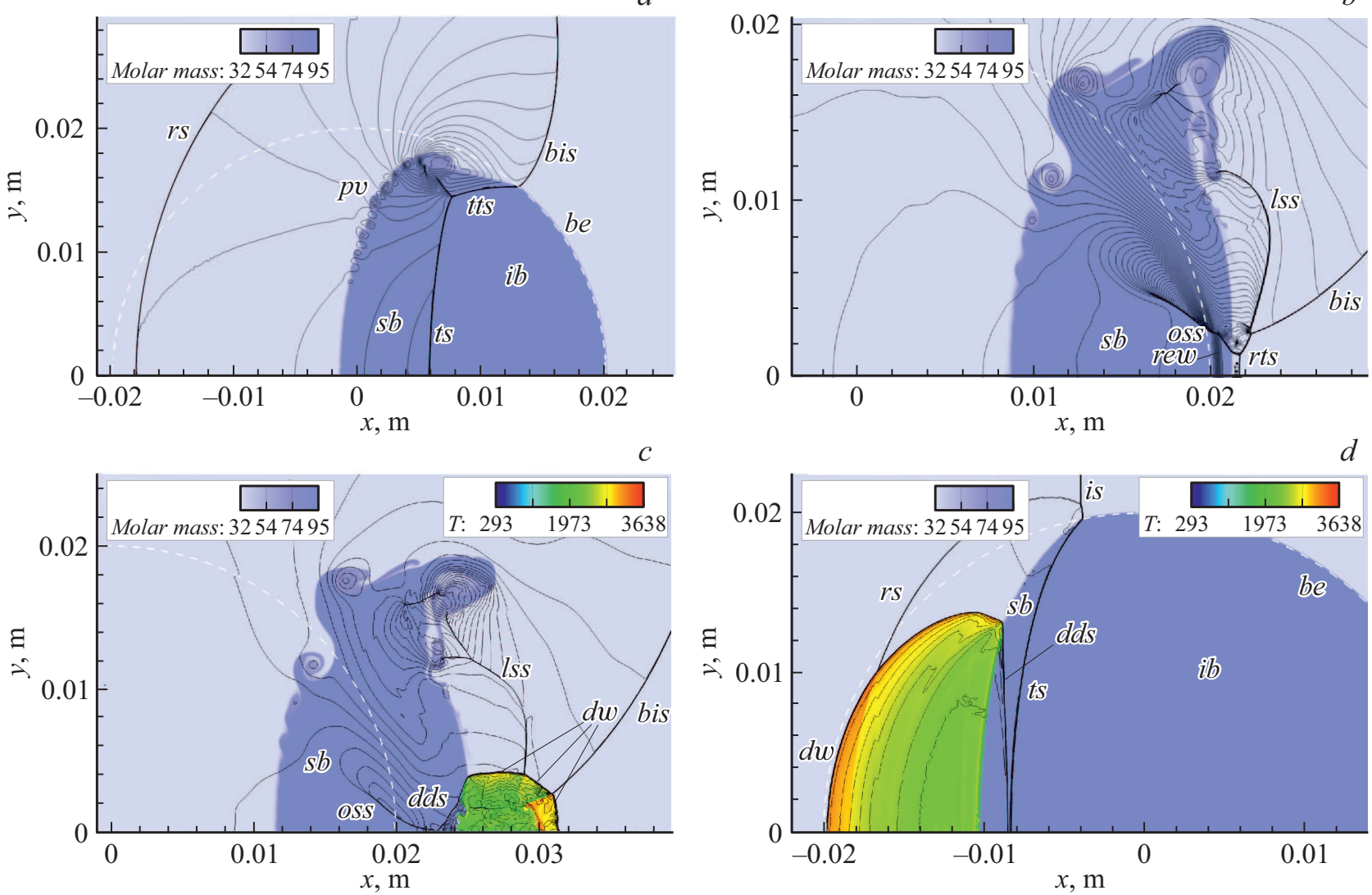

Рис. 2. Преломление ударной волны и режимы инициирования детонации. $a-$ ранняя стадия преломления при $\mathrm{M}=2.7$, $\eta=1.0 ; b-$ средняя стадия; $c$ - детонация при фокусировке вторичных скачков; $d-$ детонация при отражении более сильной волны $(\mathrm{M}=3.2)$ от пузыря. Показана верхняя половина течения, плоскость симметрии проходит по нижней границе рисунков. Центр пузыря расположен в точке $x=y=0$. Изолинии давления с экспоненциальным распределением, цветом (или градациями серого в печатной версии статьи) показаны молярная масса и температура (только значения $T>1600 \mathrm{~K}$ ); $i b, s b-$ невозмущенная и ударно-сжатая части пузыря; $b e-$ начальная граница пузыря (штриховая линия); $b i s-$ выпуклая часть волны $i s ; r s, t s-$ отраженный и прошедший скачки; $t s, o s s$ - поперечные вторичные скачки; $l s s$ - продольный вторичный скачок; rts - ретранслированный скачок; rew - отраженная волна разрежения; $d w$ - детонационная волна; $d d s-$ скачок в инертном газе, вызванный детонационной волной.

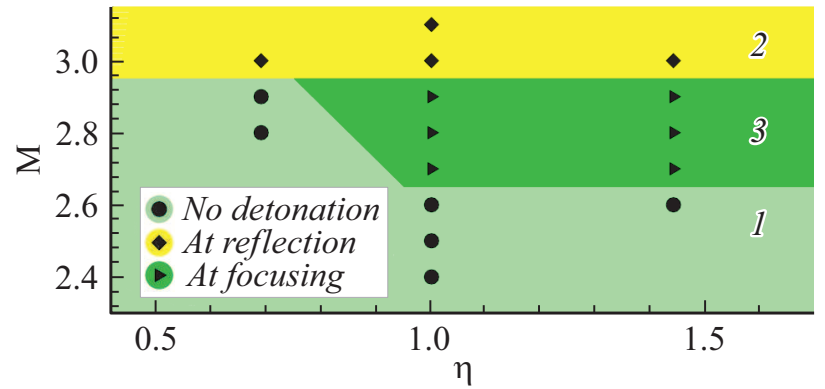

Рис. 3. Зависимость режима воспламенения от числа Маха М и отношения диаметров пузыря $\eta$. Каждый символ соответствует одному расчету для пары значений $(\mathrm{M}, \eta) .1$ - детонации нет, 2 - детонация при отражении волны, 3 - при фокусировке вторичных волн.

инициирования детонации (рис. 3). Достаточно сильные ударные волны $(\mathrm{M}>2.9)$ приводят к детонации при отражении волны независимо от формы пузыря. Для круглых $(\eta=1.0)$ и вытянутых $(\eta=1.44)$ пузырей детонация при фокусировке волн происходит при $2.7 \leq \mathrm{M} \leq 2.9$. Тривиальный режим детонации - за счет прямого разогрева в исходной волне - реализуется при $\mathrm{M} \geq 4.0$.

Таким образом, существует два механизма снижения критического числа Маха падающей волны, достаточного для инициирования детонации: за счет наличия тяжелого пузыря (он служит препятствием, от которого волна может отразиться) и ,газовой линзой“, фокусирующей волну. Первый эффект снижает критическое число Маха до $\mathrm{M}=2.9-3.0$, а второй - до $\mathrm{M}=2.7$. В обоих случаях снижение достаточно велико для того, чтобы это явление было необходимо учитывать в технических приложениях.

На основе численного моделирования взаимодействия ударной волны в горючем газе с эллиптической областью - пузырем - инертного газа показано, что 
режим инициирования детонации зависит как от интенсивности падающей волны, так и от формы пузыря. Примененная модель течения не включает эффекты вязкости, теплопроводности и диффузии, поэтому границы режимов воспламенения определены лишь приблизительно. Однако основной эффект - существенное снижение критического числа Маха за счет отражения и фокусировки волны - имеет физическую основу. Это явление необходимо учитывать в вопросах взрывобезопасности, а также можно применять как новый метод инициирования детонации в высокоскоростных системах сгорания.

\section{Финансирование работы}

Работа выполнена в НИИ механики МГУ им. М.В. Ломоносова с использованием оборудования Центра коллективного пользования сверхвысокопроизводительными вычислительными ресурсами МГУ им. М.В. Ломоносова при финансовой поддержке Совета по грантам Президента РФ (МК-3012.2019.1).

\section{Конфликт интересов}

Авторы заявляют, что у них нет конфликта интересов.

\section{Список литературы}

[1] N. Haehn, D. Ranjan, C. Weber, J. Oakley, D. Rothamer, R. Bonazza, Combust. Flame, 159 (3), 1339 (2012). https://doi.org/10.1016/j.combustflame.2011.10.015

[2] F. Diegelmann, V. Tritschler, S. Hickel, N. Adams, Combust. Flame, 163, 414 (2016). https://doi.org/10.1016/j.combustflame.2015.10.016

[3] F. Diegelmann, S. Hickel, N. Adams, Combust. Flame, 174, 85 (2016). https://doi.org/10.1016/j.combustflame.2016.09.014

[4] F. Diegelmann, S. Hickel, N. Adams, Combust. Flame, 181, 300 (2017). https://doi.org/10.1016/j.combustflame.2017.03.026

[5] P.Yu. Georgievskiy, V.A. Levin, O.G. Sutyrin, Shock Waves, 25 (4), 357 (2015). https://doi.org/10.1007/s00193-015-0557-4

[6] П.Ю. Георгиевский, В.А. Левин, О.Г. Сутырин, Письма в ЖТФ, 45 (23), 43 (2019).

DOI: 10.21883/PJTF.2021.09.50902.18651

[Пер. версия: 10.1134/S1063785019120071].

[7] V.P. Korobeinikov, V.A. Levin, Fluid Dynamics, 4 (6), 30 (1969). https://doi.org/10.1007/BF01032469

[8] S. Taki, T. Fujiwara, AIAA J., 16 (1), 73 (1978). https://doi.org/10.2514/3.60859

[9] A. Matsuo, T. Fujiwara, in AIAA 26th Thermophysics Conf. (Honolulu, USA, 1991), p. 1414.

https://doi.org/10.2514/6.1991-1414 